John Carroll University

Carroll Collected

Conversation among Physical Chemists: Strategies and Resources for Remote Teaching and Learning Catalyzed by a Global Pandemic

Andrea N. Giordano

David Gardner

William W. Kennedy

Chrystal D. Bruce

Follow this and additional works at: https://collected.jcu.edu/fac_bib_2021

Part of the Chemistry Commons, and the Higher Education Commons 


\title{
Conversation among Physical Chemists: Strategies and Resources for Remote Teaching and Learning Catalyzed by a Global Pandemic
}

\begin{abstract}
In the midst of a global pandemic in spring 2020, physical chemistry faculty gathered to share strategies and resources for teaching remotely. During this conversation, instructors created a shared document compiling the challenges they faced in spring 2020 and ways to improve teaching and learning in the physical chemistry classroom and laboratory when institutions reopened in the fall. We present a content analysis of the shared document that provides a snapshot of physical chemists' thoughts at that moment in June 2020. The themes that emerged from our analysis are assessment, choice of learning objectives, course management, opportunities, resources, student motivation, and wellbeing. We have summarized the numerous strategies, resources, and implementation ideas that were shared by participants, many of which we believe will remain in use when traditional in-person instruction resumes. Finally, the conversation connected physical chemists, strengthening our community. Continued community engagement has occurred through further synchronous conversations, asynchronous conversations on our Slack workspace, and the creation of the repository PChem Inspired Pedagogical Electronic Resource (PIPER).
\end{abstract}

KEYWORDS: Upper-Division Undergraduate, Physical Chemistry, Internet/Web-Based Learning, Computer-Based Learning, Curriculum, Laboratory Computing/Interfacing

\section{INTRODUCTION}

The pivot to remote learning that happened in spring 2020 due to the COVID-19 pandemic caused students and faculty to face numerous challenges. Chemistry instructors banded together to pool resources and devise strategies to create the best learning environment for their students while navigating personal and professional upheaval. Existing communities (e.g., VIPER $^{1}$ and POGIL-PCL ${ }^{2}$ ) demonstrated how their resources could be used remotely. The Journal of Chemical Education published Virtual Issues entitled Resources for Teaching Your Chemistry Class Online $e^{3-22}$ in March and Laboratory Learning ${ }^{23-42}$ in June that each collected 20 articles with remote learning strategies and resources. In September 2020, the Special Issue Insights Gained While Teaching Chemistry in the Time of COVID $-19^{43}$ contained over 180 papers including a handful addressing physical chemistry. ${ }^{44-48}$ The Facebook group 49 "Strategies for teaching chemistry online" was created on March 10, 2020 and had more than 3000 members by summer of 2020 . There was a clear need for a community in which instructors share resources and provide support.

When our tumultuous spring 2020 teaching concluded, many of us began to deliberately plan our future classroom and lab experiences. Institutions, including those of each coauthor, began announcing the format of fall courses: online only, face- to-face only, or some hybrid version. A small group of physical chemistry instructors were interested in talking with each other about the logistics of teaching physical chemistry in these formats. Many of us were part of other physical chemistry communities $^{50}$ including the American Chemical Society Exams Institute Physical Chemistry Exams Committee, the Molecular Education and Research Consortium in Undergraduate computational chemistRY, or MERCURY, ${ }^{51}$ the Process Oriented Guided Inquiry Learning-Physical Chemistry Lab network, or POGIL-PCL, ${ }^{2}$ and the Engaging Students in Physical Chemistry Google Group. ${ }^{52,53}$ The COVID-19 crisis accelerated the push to integrate efforts to build a community among physical chemists that was already happening. A small group of us decided to open our conversation to all physical chemists. We contacted the members of the groups mentioned above and posted to the Facebook group "Strategies for teaching chemistry online" to advertise the conversation. 
On June 18, 2020, more than 80 physical chemists gathered for a $2 \mathrm{~h}$ Zoom call to discuss the challenges we were facing, strategies for addressing those challenges, how we could implement those strategies, and ways the community could help. The meeting began with a brief introduction, and then, participants were sorted into 14 breakout rooms. A facilitator guided participants in each room through the discussion questions in Table 1. During each 15 min breakout session,

Table 1. Discussion Questions for Each Breakout Session of the Physical Chemistry Zoom Call

\begin{tabular}{ll}
$\begin{array}{c}\text { Breakout } \\
\text { Session Focus }\end{array}$ & \multicolumn{1}{c}{ Discussion Questions } \\
Laboratory/1 & $\begin{array}{c}\text { Briefly: What are the primary challenges you are facing in } \\
\text { your PChem lab this fall? } \\
\text { What strategies have you been considering implementing? }\end{array}$ \\
Laboratory/2 & $\begin{array}{c}\text { How could you envision implementing some of the } \\
\text { strategies discussed thus far? }\end{array}$ \\
& $\begin{array}{c}\text { How could the community of Physical Chemists help you? } \\
\text { Briefly: What are the primary challenges you are facing in } \\
\text { your PChem classroom this fall? }\end{array}$ \\
& $\begin{array}{c}\text { What strategies have you been considering implementing? } \\
\text { How could you envision implementing some of the } \\
\text { strategies discussed thus far? }\end{array}$ \\
& How could the community of Physical Chemists help you?
\end{tabular}

members of the group recorded their responses in a shared Google Doc (available in the Supporting Information). Groups also shared highlights with all participants using the Zoom whiteboard during a $10 \mathrm{~min}$ report-out time between each breakout session.

Our primary goal was to develop strategies to overcome the adverse circumstances created by the COVID-19 pandemic. Community building was another goal. Virtual gatherings reduce isolation for many physical chemistry instructors, who may be the only physical chemist at their institution. We created a Slack channel ${ }^{54}$ for ongoing conversation, and we organized more Zoom meetings through the summer and the 2020-2021 academic year. Additionally, the PChem Inspired Pedagogical Electronic Resource (PIPER ${ }^{55}$ ) repository was subsequently created with the hope that the resources and support created by this group will have long-term impact on the teaching and learning of physical chemistry.

This manuscript delineates the content of notes (available in the Supporting Information) created during the initial Zoom meeting. In their conversations, physical chemistry instructors discussed the challenges they were facing. They embraced new pedagogies in both the lab and the classroom. They exchanged strategies, resources, and implementation tools (available in the Supporting Information) that will improve how physical chemistry courses are conducted amidst this global pandemic and in the future in a variety of classroom formats. The content analysis of this discussion forms a snapshot of how our community came together at this meeting.

\section{METHODS}

Content analysis, ${ }^{56-59}$ a qualitative research method, was performed on the notes (available in the Supporting Information) that were recorded during the virtual meeting. There were 603 individual statements that were reviewed to identify themes and develop a coding system. Each coauthor first reviewed all statements independently. Then, we met in groups of two or four in 12 meetings over the course of several months to identify themes and codes. Themes were refined, including combining, subdividing, or adding themes, as statements began to be coded. As well, the codes were iteratively revised during the meetings before an ultimate consensus on them was reached. Table 2 shows the themes

\section{Table 2. Themes and Codes Assigned to Statements} Generated during the Breakout Sessions

\begin{tabular}{|c|c|}
\hline $\begin{array}{c}\text { Themes } \\
\text { (decreasing frequency) }\end{array}$ & Codes within Each Theme (alphabetical) \\
\hline Course management & $\begin{array}{l}\text { Data collection/hands-on activities in lab } \\
\text { Dealing with sick students } \\
\text { Flipped classroom } \\
\text { Group work } \\
\text { Insufficient time/resources } \\
\text { Modifications to course structure in response to } \\
\text { COVID (e.g., synchronous vs asynchronous } \\
\text { content, shifted schedules, structure of in-person } \\
\text { laboratories/classes, syllabus modifications) } \\
\text { Uncertainty } \\
\text { Other }\end{array}$ \\
\hline Resource & $\begin{array}{l}\text { Needed (coded with resource type) } \\
\text { Shared (coded with resource type) }\end{array}$ \\
\hline Resource type & $\begin{array}{l}\text { Activities for students to do in class or lab } \\
\text { Books } \\
\text { Computational chemistry } \\
\text { Data analysis and programming software } \\
\text { Repository and community for physical chemists } \\
\text { Teaching technology } \\
\text { Videos } \\
\text { Other }\end{array}$ \\
\hline Assessment & $\begin{array}{l}\text { Administering remote assessments } \\
\text { Cheating } \\
\text { Nontraditional assessments (e.g., oral exams, } \\
\text { creative works, presentations) } \\
\text { Shift to lower stakes (formative) assessments } \\
\text { Other }\end{array}$ \\
\hline Wellbeing & $\begin{array}{l}\text { Emotional } \\
\text { Physical }\end{array}$ \\
\hline $\begin{array}{l}\text { Student motivation/ } \\
\text { engagement }\end{array}$ & \\
\hline $\begin{array}{l}\text { Choice of learning } \\
\text { objectives } \\
\text { Opportunities }\end{array}$ & \\
\hline
\end{tabular}

and codes (subheadings under each theme) that we developed. The themes and codes were then shared with and approved by the facilitators of the 14 breakout rooms. (We are deeply grateful to the facilitators, duly named in the Acknowledgments section.) Each of the 603 statements from the meeting notes were assigned codes (typically one or two) from the list in Table 2.

During the conversation, the facilitators focused participants on strategies to address new challenges in teaching physical chemistry. Facilitators were instructed to keep the conversation about challenges brief so that more forward-looking approaches for the upcoming academic year could be identified. The 603 statements were approximately evenly distributed between lab and classroom ( 300 each) and across the four breakout sessions (average of $\sim 150$ /session ranging from $\sim 130$ to $\sim 180$ ). Participants were much more likely to provide strategy, resource, and implementation suggestions than a challenge by more than $2: 1$. 
Student Engagement Tools: Flipgrid, Zoom breakout rooms, Blackboard embedded tests, Google Collaborate, Poll Everywhere, Perusall, Piazza, Socrative, Kritik, PlayPosit, Edpuzzle, PhET simulations, Teaching Technologies H5P, Symmetry@Otterbein, and Notability.

Communication Tools: Microsoft Teams, Slack, Zoom, GroupMe, Webex, Explain Everything, Youcanbook.me, Google Meet, EquatIO, Padlet, and Workflow.
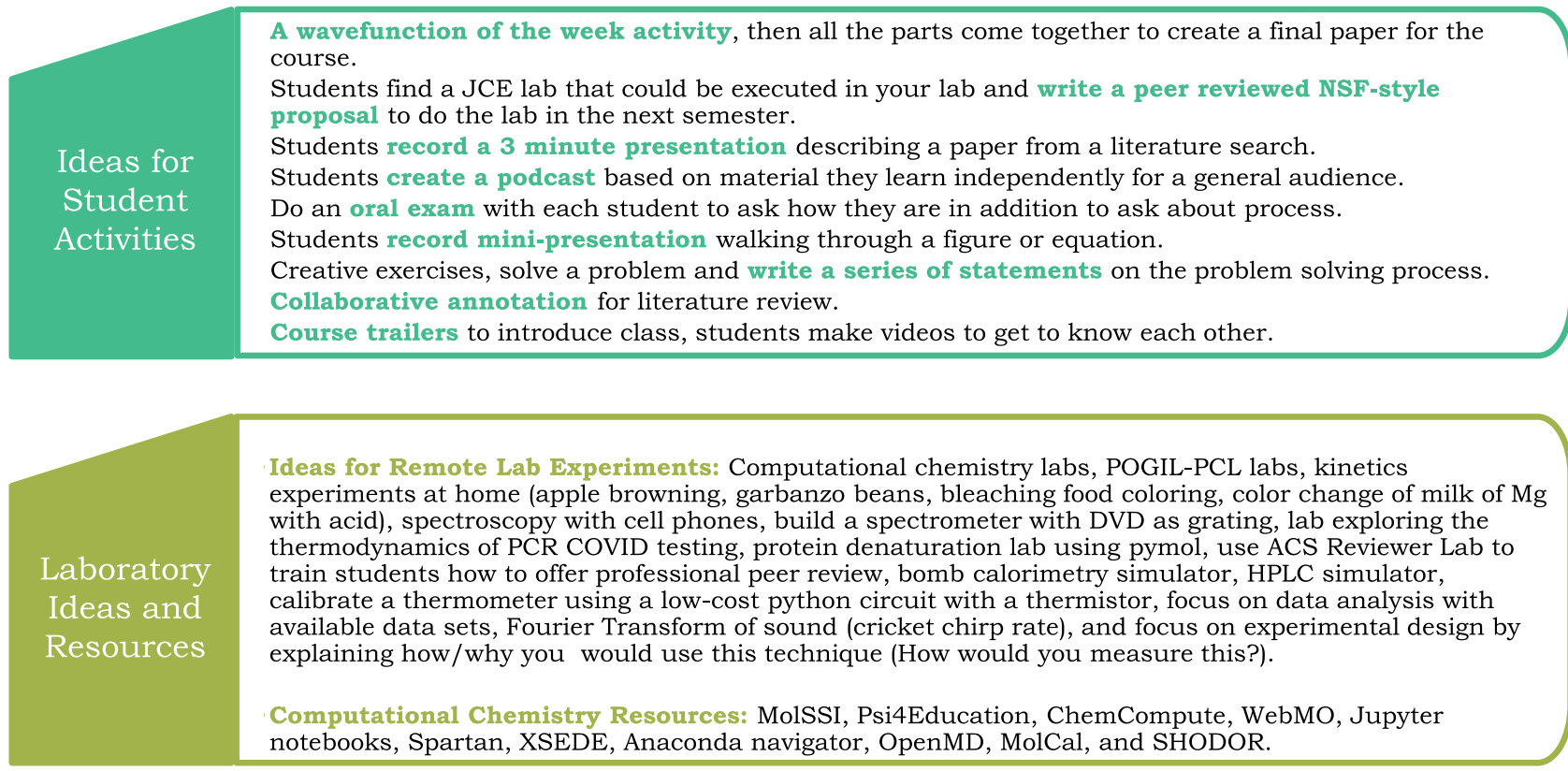

Figure 1. Summary of resources and ideas shared by faculty participants during the Physical Chemistry Zoom session. Additional information including weblinks for the shared resources are available in the Supporting Information.

\section{RESULTS AND DISCUSSION}

The themes listed in Table 2 that we identified from our discussion (assessment, choice of learning outcomes, course management, opportunities, resources, student motivation/ engagement, and wellbeing) are consistent with topics of papers in the Journal of Chemical Education Special Issue on Teaching Chemistry in the Time of COVID-19. ${ }^{43}$ The largest number of papers in the Special Issue addressed laboratory learning. Other topics in the special issue that appeared frequently included active learning and collaboration, logistics and responses to change, and testing and assessment. Clearly, these topics are on the minds of chemistry faculty everywhere.

\section{Course Management}

The course management theme had 300 statements (50\%). Many faculty faced great uncertainty as to how their institution would be operating (in person, hybrid, fully online) and how to plan for midcourse pivots. Statements such as "we're not sure what the format will be yet; most people planning for at least some of it to be online" and questions such as "what to do if campus closes mid-semester?" represent that uncertainty. Another group pointed out that they were "having to be prepared to go online at any minute". Concerns about how to balance synchronous and asynchronous activities or in-person and remote students were also apparent. Participants indicated that they "may have to accommodate students who choose to stay home and take all classes remotely, so need to offer both synchronous and asynchronous options" and faced "different constraints: $1 / 3$ of students in class and other online. How to engage both simultaneously?" Suggested strategies to combat these concerns included implementing a flipped classroom environment using class time for problem sets and discussions, making use of available teaching technology (see Figure 1) including campus Learning Management Systems (LMS) and web-meeting platforms, grouping students by time zone for those attending remotely, and recording classes for students who cannot attend for whatever reason including being diagnosed with COVID-19.

It was particularly apparent that lab courses were going to require significant adaptation. As stated by one participant, "figuring out what experiments can do without students doing the data collection is a major issue." Faculty expressed concern that they did not have enough resources (time, instrumentation, lab space) to achieve the goals of the laboratory experience, indicating that it is "hard to reconcile physical distancing of students with limited number of available instruments, but students may not be allowed to work in pairs/groups" and asking "Will there be enough time for students to rotate and complete labs if they are not working in pairs?" More existential questions like "can hands-on experiences be effectively replaced by distance labs?” were discussed. The challenges associated with group work and hands-on data collection were mentioned repeatedly by different groups, particularly in relation to physical distancing and cleaning shared instrumentation between users. For those who were having in-person classes, some planned to "still do some hands-on labs, trying to split hands-on groups into inperson and online". Strategies to address these challenges included pooling data, which was mentioned in several groups, as well as creating simulations, sharing data sets collected 
previously, designing at-home experiments, and front-loading data collection if students were abruptly sent home midsemester. Many instructors were interested in implementing more computational chemistry; one group asked "how do you move to more modeling-based labs?" The community responded with a comprehensive list of resources and ideas as shown in Figure 1 ranging from online computational tools like ChemCompute.org to training in programming and use of Jupyter notebooks. Table S1 in the Supporting Information contains a comprehensive list of the resources physical chemistry instructors shared, descriptions of those resources, and weblinks for more information.

\section{Resources and Resource Types}

The physical chemistry faculty who participated in this conversation were primarily focused on identifying strategies, resources, and implementation ideas for their courses. As a result, there were $\sim 300$ statements $(50 \%)$ that mentioned a resource. Nearly a third of those shared a teaching technology (campus Learning Management Systems, web-meeting platforms, educational apps, platforms for asynchronous communication) with a small handful requesting help with managing that technology to accomplish their learning goals. Applications such as WebEx, Zoom, Canvas, Blackboard, Perusall, Socrative, Piazza, Slack, Microsoft Teams, Explain Everything, Notability, Padlet, Flipgrid, and Google Meet were mentioned. Figure 1 provides a list of shared resources and their function. Additional information on each application as well as how to access it can be found in the Supporting Information where readers can find a table with information on 15 Student Engagement Tools, 12 Communication Tools, five Remote Lab Experiments, and 11 Computational Chemistry Resources.

The next most common subthemes under resource type were specific activities for students to perform in class or lab and ways the community of physical chemists could be a resource. Eight of the 14 breakout groups discussed POGILPCL activities, and a number of at-home laboratories were shared. A collection of computational chemistry resources and ideas for experiments were also shared in addition to data analysis and programming activities, all of which were deemed a valuable strategy for possible remote learning environments in the 2020-2021 academic year and beyond. The shared resources and ideas are in Figure 1, while the table with how they are used and where to access them is in the Supporting Information.

\section{Assessment}

Members of every breakout room discussed assessment. Many faculty were deeply concerned about the ability to assess students in an online environment, particularly with regard to cheating. One group reported that "exams were difficult to administer in virtual (sic) environment. ACS standardized test (sic) are not an option. Attempts to lock questions and require students to answer one at a time before advancing did not significantly reduce dishonesty.” A number of groups discussed shifting to more frequent, lower stakes assessments, an important strategy to reduce the achievement gap. ${ }^{60}$ For example, the advice was shared to "avoid major exams and instead, use more low stakes assessments. Weekly quizzes instead of no (sic) midterms. Junior and senior students are receptive to that." Instructors are clearly willing to assess critical thinking and problem solving in different ways as evidenced by the statement "for assessment, intentionally allow google, but ask them when and how they used it. Cite their sources. Encourages reflection. Metacognition: 'what do I need to answer this question?'” It was also suggested that faculty can ask students to "write a series of statements on the problem solving process", "incorporate Excel into exams", or make use of open book exams that may "reduce the anxiety of moving online (they were already used to working that way)".

Faculty were embracing new assessment ideas. Many groups discussed implementing oral exams, essays, presentations (including video recordings), and podcasts. One faculty member "gave an essay for the final exam (evaluate a John Donne poem in the context of the 2 nd law of thermodynamics)". These assessments provide students opportunities to improve their communication skills and reduce the role of academic dishonesty. For example, one participant had "students create a podcast based on material they learn independently". The process "required interpretation for a general audience". Instructors who assigned discussion board posts or oral exams also talked about the opportunity those provided to check in with each student individually. In discussing oral exams, ${ }^{48,61,62}$ instructors were quick to mention strategies for putting students at ease initially and ensuring fair grading with a well-established rubric. These strategies were connected to concern for the physical and emotional state of students after the abrupt transition to remote learning.

\section{Wellbeing}

Approximately 50 statements (8\%) referred to either the emotional or physical wellbeing of students and instructors. Concern for students' emotional wellbeing centered around abrupt transitions and the difficulty of balancing academic and family responsibilities from their homes. Participants realized that "students were working, dealing with family", asked "how can students pivot if they need to in the middle of the semester", and suggested that faculty "go outside your comfort zone to reach out to your students and meet with them to "talk to/checking-in on" them; do what you can to as many as (sic) of them as possible".

Any reference to physical or social distancing was coded as physical wellbeing. Lab activities and other group work are particularly difficult to manage in an environment requiring physical distancing and masks. Participants wondered "how do students work together when they are six feet apart?" and noted the challenges of communicating and working with organic solvents while wearing masks. Beyond enforcing adequate personal protective equipment, participants also pointed out that instrumentation and lab equipment will need to be cleaned between student groups. To address these challenges, groups suggested "having only one lab group come face-to-face each week and they share their data with the rest of the class" and "plan to run lab as usual with social distancing, alternating weeks with one group doing virtual".

\section{Student Motivation}

More than 30 statements (5\%) refer in some way to student motivation. A participant indicated there were "problems with student motivation" and that "my motivation too was an issue. I'm not worried about lecture, but labs are a concern." While another pointed out that "some students just stopped 'attending' class in the spring." Faculty wanted to know "how to build community online." Ways to answer this question include suggestions to "be sure to poll your students as to what formats they prefer and how they want content delivered", "separate lecture into $20 \mathrm{~min}$ chunks so (sic) that engage students", and assign "getting-to-know-you exercise (have 
students make TikTok video?) to get rapport”. It was easy for students to become overwhelmed in an online format. Suggestions to combat that challenge included "make deadlines visible and clear!" and spend time during the first week teaching students how to learn online. Several faculty noted that attendance at office hours was lackluster after the pivot to remote learning. Suggestions for improving use of office hours included having students "make 15 min appointments every week, in addition to office hours", "make each student attend an office hour on Zoom with the waiting room enabled. For example, 'Wednesday is *your* opportunity is (sic) one-onone session with professor' - messaging was key," and "call them 'tutoring hours' instead of 'office hours'”.

\section{Choice of Learning Objectives}

A few statements refer to making choices about learning objectives, particularly from the discussion on the lab experience. When students have limited lab time, faculty have to select the most essential content and skills. Participants asked questions such as "what is most important for students to get out of lab?" and suggested that instructors "switch the goals of lab to different, but still valuable skills such as exposure to primary literature, giving presentations, data analysis, etc" and "put more emphasis on data analysis and the learning objectives there". Groups suggested having students "focus on figuring out 'How would you measure this?' Explain how/why you would use this technique (focus on design)?" It was clear that instructors must "make choices about content" to focus on "takeaway skills".

\section{Opportunities}

We recognize that, although the pandemic has been incredibly disruptive, there are opportunities for the physical chemistry community. As we are forced to implement new ideas and technology, we can also develop lasting improvements of the teaching and learning of physical chemistry. For example, we have the opportunity to increase accessibility by continuing to allow students to attend class remotely. Students, even those who attended synchronous sessions, benefit from viewing recorded class activities so they can prepare for an exam or clarify content. Deploying technology strategically can increase student engagement, facilitate student learning, and improve equity. ${ }^{63}$ Thoughtful use of LMS features can benefit students in fully in-person classes. Collaborative platforms like Google Docs, Sheets, or Jamboard allow students to respond to a prompt and then see what their peers have created to investigate themes or common misconceptions. As instructors, we have had to think creatively about every aspect of our courses, and many of the new ways of doing things should become routine.

A more expansive set of transformational opportunities exists too. These are opportunities to fundamentally rethink the purpose and reasoning of current educational goals and learning outcomes. In short, we seldom consider why we teach a particular topic or why we use certain educational tools and techniques. For example, shifting to computational chemistry experiments and using programming tools teaches our students skills and knowledge that they may not have had pre-COVID. In being forced to replace in-person activities with remote learning options, we can embrace a portion of our discipline that is widely recognized as important but not always taught at the undergraduate level. Faculty have adopted computational laboratories and programming activities as a replacement for traditional in-person activities, and they should remain in the curriculum.

However, the inclusion of more computational chemistry into physical chemistry instruction highlights a significant tension in the chemistry curriculum. The breadth and scope of physical chemistry presents a significant challenge in improving instruction and learning. Indeed, physical chemistry is so expansive it is simply not reasonable to adequately cover all topics in the undergraduate setting. Individually, we all intuitively recognize this to be true, and we commit ourselves to teaching just the most important parts of the curriculum. However, as is true in other subdisciplines, it is becoming apparent that there is little consensus as to what the most important parts really are. We currently have the opportunity to focus on this conversation and evaluate the balance of breadth and depth of the curriculum.

George Bodner originally described the dominant educational paradigm in chemistry as the vaccination model. ${ }^{56}$ In this model, instruction is like a vaccination that prevents illness; exposing students to a topic, even if only briefly, is beneficial for them in case they encounter the topic later in their career. Exposure in an early course such as general chemistry is sufficient protection so that further instruction later in a course like physical chemistry is not necessary. Simply stated, in the vaccination model, proper instruction is synonymous with covering many topics. Breadth is preferable to depth. While COVID-19 did not create the feeling that there is too much to cover and not enough time to cover it all, the disruptions certainly aggravated it. This tension has always been one that instructors have had to manage. However, the pandemic shed light on how traditional instruction can encourage students to adopt superficial learning strategies (e.g., short-term memorization) rather than engage in meaningful learning. ${ }^{64}$ It is clear from the conversation that instructors are actively seeking ways for meaningful learning to occur, including guided inquiry and creative assignments as indicated in the Resources and Resources Types and Assessment sections above.

Instructors are also wrestling with the goals of chemical instruction, further complicating the breadth vs depth issue. Traditional chemistry instruction has focused almost exclusively on chemical content knowledge. However, it is becoming apparent that developing students into chemical professionals includes skills, behaviors, and modes of thinking that are not in a textbook table of contents. Instead, a significant component of the educational process involves acculturation into the chemical community through interpersonal interactions. During the pandemic, physical distancing and separation exacerbated the challenges of engaging with peers, instructors, and content, as noted by many comments in our conversation. As we have learned through extensive research in the K-12 setting, when instructors focus too narrowly on traditional content, students are less likely to be able to apply their learning in real, practical, and meaningful ways. $^{65-68}$ Instead, students are left with a very naive understanding of the actual inquiry-based nature of science. Holistic approaches that also include science processes and practice decrease the likelihood that student learning is little more than a series of isolated, unconnected topics. Forcing instructors to consider which learning outcomes are truly necessary can shift instruction to more holistic approaches rather than an overreliance on content-based approaches. Holistic pedagogical approaches provide opportunities for innovative assessments that align with the knowledge, skills, 
behaviors, and modes of thinking students need to become practicing chemical professionals.

\section{Community Needs and Follow-Up Activities}

It was apparent from the turnout and discussion that there is a real desire for physical chemists to gather and share resources, strategies, and support. During the breakout sessions, faculty were asked to identify how the community could be of assistance. Many faculty requested a repository of resources "for remote learning such as computational experiments, videos, or data/results from experiments", which has since been created as the PIPER repository. ${ }^{55}$ The PIPER repository contains articles, books, computational resources, data sets, laboratory activities, links to other useful Web sites, and additional resources. Faculty may contribute resources to the repository through the "Help us Build" link on the web page. It was designed for instructors to find and share resources for teaching physical chemistry. We strongly encourage the interested reader to explore the PIPER repository as well as the resources in the Supporting Information of this article.

Additionally, a Slack workspace with over 130 members now exists for asynchronous communication within the community. ${ }^{54}$ Four additional synchronous conversations have taken place via Zoom since the initial meeting: a discussion of Flower Darby's Small Teaching Online ${ }^{69}$ in June, a discussion focusing on challenges in the laboratory in August, and check-in conversations in October 2020 and April 2021. Each of these follow-up conversations, which were on more focused topics, had about 30 participants, and in each, a crowd-sourced set of notes was created. These tangible outcomes from the community conversation came from requests at the initial meeting in June.

\section{CONCLUSION}

Given the challenges and uncertainties associated with the global coronavirus pandemic, faculty were focused on how to teach effectively under these new circumstances. By June 2020, the community had largely identified most of the major challenges associated with teaching physical chemistry in the current environment. The large number of suggestions and resources that were shared prove that faculty were already familiar with technological solutions and likely had experience with them prior to the start of the pandemic. This observation highlights one reason the community is so important. Individually, we recognize the gaps in our own skill set to address various challenges and problems. However, collectively, the community has a broad range of expertise and backgrounds.

Many of the comments from the meeting speak to a desire for a high-quality learning experience in our new environment. Faculty wish to retain engaging material and keep vital interactions intact. As a result, we find ourselves rethinking how we structure our classes, what we ask students to do, how we assess learning, and how we maintain motivation and wellbeing during a difficult time. We found that our colleagues have discovered creative and innovative ways of doing all of this, and we can learn from each other through the community of physical chemists. Ultimately, in addressing the challenges presented by the coronavirus pandemic as a community, we will not only teach better in the current environment but also teach better as we return to the traditional face-to-face interactions. It is too early to know the long-term impact of these changes. We cannot yet answer questions such as how many faculty will continue to use the resources and ideas identified during the conversation and collected in Figure 1 or if computational chemistry will be more integrated into the physical chemistry curriculum, for example. We implore the physical chemistry community to continue to engage with each other, use and contribute to the PIPER web page, reflect on the changes they have made as a result of disruptions caused by the COVID-19 global pandemic, and evaluate those that have improved the teaching and learning of physical chemistry.

\section{ACKNOWLEDGMENTS}

The authors are tremendously grateful to the participants who generated the document they analyzed. Their expertise and concern for student learning was apparent during the conversation and in the output they created. The authors are also immensely thankful for the facilitators of the breakout sessions: Laine Berghout, David Styers-Barnett, Alex Grushow, Sally Hunnicutt, Diane Miller, Ashley Ringer McDonald, Ruthanne Paradise, Ellen Robertson, Jodye Selco, Steve Singleton, and Rob Whitnell. The entire physical chemistry community is thankful that Steve Singleton created the PIPER repository. It has been a fantastic resource. The authors would also like to thank Ben Kennerly for designing the graphical abstract.

\section{REFERENCES}

(1) Benatan, E.; Dene, J.; Stewart, J. L.; Eppley, H. J.; Watson, L. A.; Geselbracht, M. J.; Williams, B. S.; Reisner, B. A.; Jamieson, E. R.; Johnson, A. R. JCE VIPEr: An Inorganic Teaching and Learning Community. J. Chem. Educ. 2009, 86 (6), 766. 
(2) Hunnicutt, S. S.; Grushow, A.; Whitnell, R. Guided-Inquiry Experiments for Physical Chemistry: The POGIL-PCL Model. J. Chem. Educ. 2015, 92 (2), 262-268.

(3) Holmes, J. L. JCE Chemical Education Xchange. J. Chem. Educ. 2013, 90 (1), 11-14

(4) Leontyev, A.; Houseknecht, J. B.; Maloney, V.; Muzyka, J. L.; Rossi, R.; Welder, C. O.; Winfield, L. OrganicERs: Building a Community of Practice for Organic Chemistry Instructors through Workshops and Web-Based Resources. J. Chem. Educ. 2020, 97 (1), 106-111.

(5) Hedtrich, S.; Graulich, N. Using Software Tools To Provide Students in Large Classes with Individualized Formative Feedback. J. Chem. Educ. 2018, 95 (12), 2263-2267.

(6) Casanova, R. S.; Civelli, J. L.; Kimbrough, D. R.; Heath, B. P.; Reeves, J. H. Distance Learning: A Viable Alternative to the Conventional Lecture-Lab Format in General Chemistry. J. Chem. Educ. 2006, 83 (3), 501.

(7) Loveland, W.; Gallant, A.; Joiner, C. The Living Textbook of Nuclear Chemistry: A Peer-Reviewed, Web-Based, Education Resource. J. Chem. Educ. 2004, 81 (11), 1670.

(8) Davenport, J. L.; Rafferty, A. N.; Yaron, D. J. Whether and How Authentic Contexts Using a Virtual Chemistry Lab Support Learning. J. Chem. Educ. 2018, 95 (8), 1250-1259.

(9) Mahaffy, P. G.; Holme, T. A.; Martin-Visscher, L.; Martin, B. E.; Versprille, A.; Kirchhoff, M.; McKenzie, L.; Towns, M. Beyond "Inert" Ideas to Teaching General Chemistry from Rich Contexts: Visualizing the Chemistry of Climate Change (VC3). J. Chem. Educ. 2017, 94 (8), 1027-1035.

(10) Smith, D. K. ITube, YouTube, WeTube: Social Media Videos in Chemistry Education and Outreach. J. Chem. Educ. 2014, 91 (10), 1594-1599.

(11) Benedict, L.; Pence, H. E. Teaching Chemistry Using StudentCreated Videos and Photo Blogs Accessed with Smartphones and Two-Dimensional Barcodes. J. Chem. Educ. 2012, 89 (4), 492-496.

(12) Lichter, J. Using YouTube as a Platform for Teaching and Learning Solubility Rules. J. Chem. Educ. 2012, 89 (9), 1133-1137.

(13) Kwan, A. H.; Mobli, M.; Schirra, H. J.; Wilson, J. C.; Jones, O. A. H. Video with Impact: Access to the World's Magnetic-Resonance Experts for the Scientific-Education Community. J. Chem. Educ. 2019, 96 (1), 159-164

(14) Rose, J.; Pennington, R.; Behmke, D.; Kerven, D.; Lutz, R.; Paredes, J. E. B. Maximizing Student Engagement Outside the Classroom with Organic Synthesis Videos. J. Chem. Educ. 2019, 96 (11), 2632-2637.

(15) Winkelmann, K.; Keeney-Kennicutt, W.; Fowler, D.; Macik, M. Development, Implementation, and Assessment of General Chemistry Lab Experiments Performed in the Virtual World of Second Life. J. Chem. Educ. 2017, 94 (7), 849-858.

(16) Winschel, G. A.; Everett, R. K.; Coppola, B. P.; Shultz, G. V.; Lonn, S. Using Jigsaw-Style Spectroscopy Problem-Solving To Elucidate Molecular Structure through Online Cooperative Learning. J. Chem. Educ. 2015, 92 (7), 1188-1193.

(17) Jones, O. A. H.; Spichkova, M.; Spencer, M. J. S. Chirality-2: Development of a Multilevel Mobile Gaming App To Support the Teaching of Introductory Undergraduate-Level Organic Chemistry. J. Chem. Educ. 2018, 95 (7), 1216-1220.

(18) Ranga, J. S. Multipurpose Use of Explain Everything IPad App for Teaching Chemistry Courses. J. Chem. Educ. 2018, 95 (5), 895898.

(19) Winter, J.; Wentzel, M.; Ahluwalia, S. Chairs!: A Mobile Game for Organic Chemistry Students To Learn the Ring Flip of Cyclohexane. J. Chem. Educ. 2016, 93 (9), 1657-1659.

(20) Esvan, Y. J.; Zeinyeh, W. Basics of Fourier Transform Applied to NMR Spectroscopy: An Interactive Open-Source Web Application. J. Chem. Educ. 2020, 97 (1), 263-264.

(21) Christiansen, M. A.; Nadelson, L.; Etchberger, L.; Cuch, M.; Kingsford, T. A.; Woodward, L. O. Flipped Learning in Synchronously-Delivered, Geographically-Dispersed General Chemistry Classrooms. J. Chem. Educ. 2017, 94 (5), 662-667.
(22) Kohnle, A.; Benfield, C.; Hähner, G.; Paetkau, M. Interactive Simulations To Support Quantum Mechanics Instruction for Chemistry Students. J. Chem. Educ. 2017, 94 (3), 392-397.

(23) Moozeh, K.; Farmer, J.; Tihanyi, D.; Nadar, T.; Evans, G. J. A Prelaboratory Framework Toward Integrating Theory and Utility Value with Laboratories: Student Perceptions on Learning and Motivation. J. Chem. Educ. 2019, 96 (8), 1548-1557.

(24) Stephenson, N. S.; Duffy, E. M.; Day, E. L.; Padilla, K.; Herrington, D. G.; Cooper, M. M.; Carmel, J. H. Development and Validation of Scientific Practices Assessment Tasks for the General Chemistry Laboratory. J. Chem. Educ. 2020, 97 (4), 884-893.

(25) Flaherty, A.; O’Dwyer, A.; Mannix-McNamara, P.; Leahy, J. J. Aligning Perceptions of Laboratory Demonstrators' Responsibilities To Inform the Design of a Laboratory Teacher Development Program. J. Chem. Educ. 2017, 94 (8), 1007-1018.

(26) Duis, J. M.; Schafer, L. L.; Nussbaum, S.; Stewart, J. J. A Process for Developing Introductory Science Laboratory Learning Goals To Enhance Student Learning and Instructional Alignment. J. Chem. Educ. 2013, 90 (9), 1144-1150.

(27) Bretz, S. L. Evidence for the Importance of Laboratory Courses. J. Chem. Educ. 2019, 96 (2), 193-195.

(28) Galloway, K. R.; Bretz, S. L. Measuring Meaningful Learning in the Undergraduate General Chemistry and Organic Chemistry Laboratories: A Longitudinal Study. J. Chem. Educ. 2015, 92 (12), 2019-2030.

(29) Avargil, S.; Bruce, M. R. M.; Amar, F. G.; Bruce, A. E. Students' Understanding of Analogy after a CORE (Chemical Observations, Representations, Experimentation) Learning Cycle, General Chemistry Experiment. J. Chem. Educ. 2015, 92 (10), 1626-1638.

(30) Sandi-Urena, S.; Cooper, M.; Stevens, R. Effect of Cooperative Problem-Based Lab Instruction on Metacognition and ProblemSolving Skills. J. Chem. Educ. 2012, 89 (6), 700-706.

(31) Rodriguez, J.-M. G.; Towns, M. H. Modifying Laboratory Experiments To Promote Engagement in Critical Thinking by Reframing Prelab and Postlab Questions. J. Chem. Educ. 2018, 95 (12), 2141-2147.

(32) Teichert, M. A.; Tien, L. T.; Dysleski, L.; Rickey, D. Thinking Processes Associated with Undergraduate Chemistry Students' Success at Applying a Molecular-Level Model in a New Context. J. Chem. Educ. 2017, 94 (9), 1195-1208.

(33) Shultz, G. V.; Li, Y. Student Development of Information Literacy Skills during Problem-Based Organic Chemistry Laboratory Experiments. J. Chem. Educ. 2016, 93 (3), 413-422.

(34) Walker, J. P.; Van Duzor, A. G.; Lower, M. A. Facilitating Argumentation in the Laboratory: The Challenges of Claim Change and Justification by Theory. J. Chem. Educ. 2019, 96 (3), 435-444.

(35) Xu, H.; Talanquer, V. Effect of the Level of Inquiry on Student Interactions in Chemistry Laboratories. J. Chem. Educ. 2013, 90 (1), 29-36.

(36) Cacciatore, K. L.; Sevian, H. Incrementally Approaching an Inquiry Lab Curriculum: Can Changing a Single Laboratory Experiment Improve Student Performance in General Chemistry? J. Chem. Educ. 2009, 86 (4), 498.

(37) Reynders, G.; Suh, E.; Cole, R. S.; Sansom, R. L. Developing Student Process Skills in a General Chemistry Laboratory. J. Chem. Educ. 2019, 96 (10), 2109-2119.

(38) Stieff, M.; Werner, S. M.; Fink, B.; Meador, D. Online Prelaboratory Videos Improve Student Performance in the General Chemistry Laboratory. J. Chem. Educ. 2018, 95 (8), 1260-1266.

(39) Hennah, N.; Seery, M. K. Using Digital Badges for Developing High School Chemistry Laboratory Skills. J. Chem. Educ. 2017, 94 (7), 844-848.

(40) Bretz, S. L.; Fay, M.; Bruck, L. B.; Towns, M. H. What Faculty Interviews Reveal about Meaningful Learning in the Undergraduate Chemistry Laboratory. J. Chem. Educ. 2013, 90 (3), 281-288.

(41) Velasco, J. B.; Knedeisen, A.; Xue, D.; Vickrey, T. L.; Abebe, M.; Stains, M. Characterizing Instructional Practices in the Laboratory: The Laboratory Observation Protocol for Undergraduate STEM. J. Chem. Educ. 2016, 93 (7), 1191-1203. 
(42) Gron, L. U.; Bradley, S. B.; McKenzie, J. R.; Shinn, S. E.; Teague, M. W. How To Recognize Success and Failure: Practical Assessment of an Evolving, First-Semester Laboratory Program Using Simple, Outcome-Based Tools. J. Chem. Educ. 2013, 90 (6), 694-699.

(43) Holme, T. A. Introduction to the Journal of Chemical Education Special Issue on Insights Gained While Teaching Chemistry in the Time of COVID-19. J. Chem. Educ. 2020, 97 (9), 2375-2377.

(44) Baker, R. M.; Leonard, M. E.; Milosavljevic, B. H. The Sudden Switch to Online Teaching of an Upper-Level Experimental Physical Chemistry Course: Challenges and Solutions. J. Chem. Educ. 2020, 97 (9), 3097-3101.

(45) Al-Soufi, W.; Carrazana-Garcia, J.; Novo, M. When the Kitchen Turns into a Physical Chemistry Lab. J. Chem. Educ. 2020, 97 (9), 3090-3096.

(46) Bopegedera, A. M. R. P. Using Familiar and New Assessment Tools in Physical Chemistry Courses During COVID-19. J. Chem. Educ. 2020, 97 (9), 3260-3264.

(47) McDowell, S. A. C. Asynchronous Online Assessment of Physical Chemistry Concepts in the Time of COVID-19. J. Chem. Educ. 2020, 97 (9), 3256-3259.

(48) Giordano, A. N.; Christopher, C. R. Repurposing Best Teaching Practices for Remote Learning Environments: Chemistry in the News and Oral Examinations During COVID-19. J. Chem. Educ. 2020, 97 (9), 2815-2818.

(49) DeKorver, B.; Chaney, A.; Herrington, D. Strategies for Teaching Chemistry Online: A Content Analysis of a Chemistry Instruction Online Learning Community during the Time of COVID19. J. Chem. Educ. 2020, 97 (9), 2825-2833.

(50) MERCURY Is a Community of Computational Chemistry Teacher-Scholars at Primarily Undergraduate Institutions. POGILPCL Is a Community Dedicated to Developing Physical Chemistry Lab Experiments That Use the POGIL Framework.

(51) Shields, G. C. Twenty Years of Exceptional Success: The Molecular Education and Research Consortium in Undergraduate Computational Chemistry (MERCURY). Int. J. Quantum Chem. 2020, 120 (20), No. e26274.

(52) To Join the Google Group, Please Contact Craig Teague at cteague@cornellcollege.edu.

(53) Teague, C. M.; Gardner, D. E. Engaging Students in Physical Chemistry; American Chemical Society: Washington D.C., 2018.

(54) To join the slack channel, please contact corresponding author C.D.B. at cbruce@jcu.edu.

(55) Singleton, S. PChem Inspired Pedagogical Electronic Resource (PIPER). https://chemistry.coe.edu/piper/public/ (accessed 202105-25).

(56) Corbin, J.; Strauss, A. Basics of Qualitative Research (3rd Ed.): Techniques and Procedures for Developing Grounded Theory; SAGE Publications, Inc., 2008.

(57) Krippendorff, K. Content Analysis: An Introduction to Its Methodology, 2nd ed.; SAGE Publications: Thousand Oaks, CA, 2004.

(58) Creswell, J. W. Research design: Qualitative, Quanitative, and Mixed Methods Approaches, 3rd ed.; Sage Publications, Inc: Thousand Oaks, CA, 2009; pp xxix, 260-xxix, 260.

(59) Hsieh, H.-F.; Shannon, S. E. Three Approaches to Qualitative Content Analysis. Qual. Health Res. 2005, 15 (9), 1277-1288.

(60) Harris, R. B.; Mack, M. R.; Bryant, J.; Theobald, E. J.; Freeman, S. Reducing Achievement Gaps in Undergraduate General Chemistry Could Lift Underrepresented Students into a "Hyperpersistent Zone. Sci. Adv. 2020, 6 (24), eaaz5687.

(61) Joughin, G. Dimensions of Oral Assessment. Assess. Eval. High. Educ. 1998, 23 (4), 367-378.

(62) Roecker, L. Using Oral Examination as a Technique To Assess Student Understanding and Teaching Effectiveness. J. Chem. Educ. 2007, 84 (10), 1663.

(63) Bancroft, S. F.; Fowler, S. R.; Jalaeian, M.; Patterson, K. Leveling the Field: Flipped Instruction as a Tool for Promoting Equity in General Chemistry. J. Chem. Educ. 2020, 97 (1), 36-47.
(64) Gardner, D. E. Strategies for Engagement: Enhancing Your Teaching. Engaging Students in Physical Chemistry; American Chemical Society, 2018; Vol. 1279, p 1.

(65) Bybee, R. W. Achieving Scientific Literacy: From Purposes to Practices; Heinemann: Portsmouth, NH, 1997.

(66) Bybee, R.; Carlson Powell, J.; Trowbridge, Leslie, W. Teaching Secondary School Science: Strategies for Developing Scientific Literacy; Pearson Prentice Hall, 2008.

(67) National Research Council. Inquiry and the National Science Education Standards: A Guide for Teaching and Learning; The National Academies Press: Washington D.C., 2000.

(68) National Research Council. A Framework for K-12 Science Education: Practices, Crosscutting Concepts, and Core Ideas; The National Academies Press: Washington D.C., 2012.

(69) Darby, F.; Lang, J. Small Teaching Online: Applying Learning Science to Online Classes; Wiley: San Francisco, CA, 2019. 